\title{
A PEDRA, O SAPO E O LIVRO PARA CRIANÇAS
}

\author{
THE STONE, THE FROG AND THE BOOK FOR CHILDREN
}

\author{
Miguel CARVALHO \\ PUC - RJ \\ miguelzin@yahoo.com.br
}

\begin{abstract}
Resumo: A linguagem e a poesia juntas formam o miolo da discussão colocada nesse artigo. Ou ainda, a reflexão crítica a partir delas. Que é também a motivação da escrita desse texto e o propósito na criação para a literatura infantil. A linguagem adotada neste texto não é acadêmica, mas o tratamento e o cuidado são tão sérios quanto cobrados na academia. Os autores tratados basicamente são aproveitados de dois modos: os que provocam-me reflexões mais teóricas, em especial Constantino Bértolo e Octávio Paz, e outros reflexões poéticas: Manoel de Barros e Guimarães Rosa. Esses dois últimos, entretanto, não entrarem propriamente na discussão, senão como alusão poética. Manoel de Barros, um pouco mais, abre e encerra o texto. São autores que me fizeram refletir teórica e criticamente a partir da literatura. A partir de textos poéticos. Outros também temperam o texto, mas pouco e sem inserções diretas. São contribuições da ordem do invisível, mas igualmente importantes. $O$ ponto de partida é a outra margem. O olhar distanciado, possível através da leitura e da literatura. Seu potencial de distração, transcendência e, portanto, reflexão. Revelar o já conhecido, de um outro modo. O assunto se desenvolve numa costura dialógica com Bértolo e Paz e encerra apontando, na literatura infantil, ou naquela ilustrada, a natureza plural que potencializa toda a discussão anterior.
\end{abstract}

Palavras-chave: Livro Infantil. Poesia. Linguagem. Reflexão crítica.

\begin{abstract}
Language and poetry together form the core of the discussion set forth in this article. Or still, the critical reflection from them. That is also the motivation of writing this text and the purpose in creation for children's literature. The language adopted in is not academic, but treatment and care are as serious as being charged in academia. The authors treated basically are used in two ways: those that provoke more theoretical reflections, especially Constantino Bértolo and Octávio Paz, and other poetic reflections: Manoel de Barros and Guimarães Rosa. These last two, however, do not properly enter into the discussion, but as a poetic allusion. Manoel de Barros, a little more, opens and closes the text. They are authors who have made me reflect theoretically and critically from the literature. From poetic texts. Others also temper the text, but little and without direct insertions. They are invisible contributions, but equally important. The starting point is the other bank. The distanced look, possible through reading and literature. Its potential for distraction, transcendence, and therefore reflection. Reveal the already known, in another way. The subject develops in a dialogical seam with Bértolo and Paz and ends by pointing out, in children's literature, or in that illustrated one, the plural nature that potentiates all previous discussion.
\end{abstract}


Keywords: Children book. Poetry. Language. Critical reflection.

"Poesia é a infância da língua."

Manoel de Barros

\section{Introdução}

Eu queria escrever como escreve Manoel de Barros ou João Guimarães Rosa. Queria crescer até virar criança. Estudei para ser palhaço e ouvi dizer que palhaço é a busca por ser criança. A busca por olhar o mundo de novo como olham as crianças. Voltar à curiosidade delas. Não tenho saudade de ser criança, não é isso. Eu nem lembro direito como era. $E$ do que lembro, sinceramente, tem vezes que não gosto. Penso que o que gostaria era voltar a maravilhar bobagens, enxergar poesia no grilo, profundidade no sapo. Queria verdadeiramente escrever esse artigo assim. No entanto, é tudo tão sério na academia, que, às vezes nem a criança, nem o palhaço tem lugar. Então é assim, Manoel, Rosa, o sapo, a pedra, o palhaço estão todos aqui subvertendo a ideia desse lugar.

Isso tudo é para dizer que o motivo que produzo livro para crianças é exatamente o mesmo motivo que escrevo este texto. Os sentimentos e as razões de inventar novas histórias para crianças são idênticos ao de inventar novas questões para a academia. Incluo as inseguranças dessas práticas também. Mas falo disso para frente. Primeiro, preciso organizar as pedras, afinar os sapos, para não dizer bobagens.

Sei menos de teoria ou crítica literária do que de sapos. Não sei se o que digo é novo, velho ou bobo. Mas as crianças, às vezes não sabendo, fazem algumas perguntas que entornam gente grande. Como na academia muitas vezes mais importa como é a pergunta do que a resposta, estou contando com essa sorte...Posso falar um pouco mais de ilustração também. E de ser ilustrador. Para tentar descontar o que não sei das palavras. E partindo da liberdade de ser criança na academia, de repente tropeço bonito e entorto gente grande com perguntas... Quem sabe? 
Para ter ideia do que dizer, porque ninguém cria no vazio, procurei Constantino Bértolo, Octávio Paz, Mikhail Bakhtin, Pier Paolo Pasolini, Maria Nikolajeva, Carole Scott, Rui de Oliveira, Sophie Van Der Linden e Gamba Jr. Embora nem todos eles iremos encontrar nesse texto. São, no entanto, referências invisíveis, mas que faço questão de revelá-las, porque são de fundamental importância.

Constantino Bértolo (2015) analisou pesquisas sobre leitura e escreveu Ler para que? Fronteiras e Horizontes em Abril de 2015 para a revista digital Emília. Na verdade as ideias jáhaviam sido apresentadas pelo autor um ano antes no evento Conversas ao Péda Página IV que aconteceu em São Paulo. Acho corajoso o que ele diz, porque ele aponta o feio, onde muita gente acha bonito, mas, também "não desafina com o coro", como ele mesmo diz.

Quando alguém diz que o limo na pedra é bonito, ele concorda. Mas lembra que escorrega quando pisa. Ele é do tipo de gente que também vai admirar o rio quando ele está bem fraquinho, com pouca água. Fácil é admirar rio cheio, tomar banho na ducha forte da cachoeira, apreciar a cachoeira. No entanto, o rio fraco não levanta areia. Assimpode-sever a beleza do fundo. E os perigos escondidos nas pedras submersas. Claro que isso não ésómérito do Constantino Bértolo. Os outros autores aqui apontados também fazem assim, mas diferente. Cada um do seu jeito de olhar para o sapo e admirar também a pedra.

Em Octávio Paz (1982), como contraponto, busca-se a noção de poema e poesia. A já bastante conhecida forma como ele soube diferenciá-las. E principalmente, a ideia de transcendência que associa à poesia. A transcendência como transgressão da linguagem. $E$ também todo 0 conhecimento e as reflexões acerca da linguagem. Tão profundas e enriquecedoras.

Os outros entrarão pouco. Às vezes no invisível, mas não menos importantes. São autores que no meio do caminho, souberam me apontar a beleza das pedras e dos sapos. Souberam me provocar a olhar o revés e a distrair-me como crianças. Por isso, ainda que não tenhamos contribuições explícitas neste texto, muitas ideias são fruto e serão construções sobre esse alicerces. 
Para iniciar esta reflexão, podemos trazer Bértolo. No já citado texto, ele diz que uma recente pesquisa sobre leitura aponta diferentes motivos pelos quais as pessoas leem. O primeiro dele diz que lemos por entretenimento. Acho que ele achou bonita a palavra. Trouxe o dicionário para ajudar. Mas percebeu, a princípio, que entreter como objetivo da leitura seria como pensar o rio para tomar banho de cachoeira.

\begin{abstract}
Divertir-se, nesse sentido, seria atingir o contentamento próprio, o que pressupõe que antes havia um descontentamento, uma carência. Daí, se deduzir que, quem incita a leitura por entretenimento, ou bem quer que deixemos de fazer aquilo que temos que fazer, ou muito conscientes de algum descontentamento que nos pressiona, desejariam que satisfizéssemos nossa carência com um substituto: a leitura, o que fomentaria, assim, a irresponsabilidade e o autoengano. (...) (BÉRTOLO, 2015, p. 66)
\end{abstract}

E assimo rio torna-se atrativo turístico. Daqueles lugares que, porque são bonitos, atraem gente. Muita gente. Todo tipo de gente. Onde tem gente, mais gente quer ir. E fica sendo ruim. Estraga."Entreter-se esconderia, assim, sua verdadeira face: a aceitação dos valores dominantes." (BÉRTOLO, 2015, p. 68)

Entretenimento rima com distração, diz o dicionário que leu Bértolo. Essa distração parece até ruim, boba, traiçoeira e desimportante. Mas játentou, assim, no sabido, alcançar a distração? Já tentou se esforçar para ficar distraído? Conseguiu se distrair voluntariamente? Ou seja, mudar o foco de atenção para outro ponto? Pois é. Ninguém alcança a distração como facilidade. Mas cai nela. Por acidente mais do que por estratégia. E fica a dúvida: sendo desimportante, não deveria ser mais fácil? Essa é a inteligência das crianças: a distração. Essa é a busca do palhaço: distrair-se, de verdade verdadeira, para se assustar com o jáconhecido. E das duas uma: ou ele treina muito, para enganar todo mundo, ou ele vira criança, bocó. Como Barros e Rosa. Que não se sabe se treinaram muito ou se conseguiram virar bocóde dom.

Octávio Paz completa os distraídos:

Um homem que se distrai nega o mundo moderno. Ao fazê-lo, joga o todo pelo todo. Intelectualmente, sua decisão não é diferente da do suicida por sede de conhecer o que hádo outro lado da vida.O distraído se pergunta: o que hádo outro lado da vigília e da razão? A distração que dizer: atração pelo reverso deste mundo. (PAZ, 1982, p.46) 
Valorizo os distraídos porque aproximam-se das crianças e dos palhaços. Invejo porque têm poder de transcendência. Mas assim, quase no discutido, na surpresa. Buscam conhecer o reverso, o outro lado, a outra margem de Guimarães Rosa e Octávio Paz também:

... a pedra da estátua, o vermelho do quadro, a palavra do poema, não são pura e simplesmente pedra, cor, palavra: encarnam algo que os transcende e ultrapassa. Sem perder seus valores primários, seu peso original, são também como pontes que nos levam àoutra margem, portas que se abrem para outro mundo de significados impossíveis de serem ditos pela mera linguagem. (PAZ, 1982, p.27)

Assim, é poeta alguém que transcende os limites da linguagem. É poesia essa transcendência.

Dito isso, posso afirmar: escrevo para os interessados no revés. Aqui e no livro infantil. O que está invisível, o que estápor trás da linguagem me interessa. O que estápor trás da poesia. E, portanto, o que está por trás dos livros que produzo para crianças e dos textos que produzo para a academia.

Se a distração está na ordem do entretenimento, é na ordem do conhecimento que encontra-se a transcendência, pois ultrapassa a linguagem. Ir para outra margem traz em si o conhecer.

Bértolo, em seguida, analisou outro motivo da leitura: a busca pelo conhecimento. O livro como uma caixa de coisas por saber, ou uma porta para outro lugar que nunca, nunca, poderíamos ter estado. Às vezes lugar que existe, às vezes lugar inventado.

Por meio da leitura se argumenta, conhecemos mundos e vidas, aos que não poderíamos ter acesso de outra forma." (...) "É importante lembrar, contudo, que esse conhecimento que aleitura proporciona -sobretudo quando se trata da leitura de ficção é basicamente um conhecimento virtual, ou seja, um conhecimento por via cumulativa ou por recordação, nas palavras de Sócrates, do real. Nesse sentido o conhecer que proporciona a leitura éum pseudoconhecimento ou um conhecimento brando que arrasta consigo a ilusão de se confundir com o conhecimento real. Confusão que culmina narrativamente na loucura de Dom Quixote ou na cegueira afetiva de Emma Bovary. Um conhecer virtual que pode provocar turbulências no processo de "retorno ao real". (BÉRTOLO, 2015, p.68) 
Ainda que entenda-se esse conhecimento como virtual, ir para um lugar, mesmo inventado, faz olhar para o lugar de onde viemos. Olhar a margem de cá, de onde estamos, pela perspectiva da margem de lá, para onde o livro nos levou, éconhecer mais o lugar que habitamos.

Claro que há os que se perdem pelo caminho, se assusta com moinhos e não volta mais, como apontou Bértolo.

Mas, para além dos possíveis transtornos causados por uma grosseira confusão do real e do virtual, é evidente que a leitura pode proporcionar esquemas ou pautas para o conhecimento dos mecanismos das relações humanas, a criação, manipulação e uso dos sentimentos, ou para a análise das relações de poder dentro de uma sociedade. (BÉRTOLO, 2015, p.70)

Contudo, o conhecimento continua sendo interesse e objetivo na produção literária para crianças. Não só o conhecimento que mofa com Visconde de Sabugosa no Sítio do Pica-pau Amarelo de Monteiro Lobato, perdido na estante. Mas também o conhecimento que está na experiência vivida por Dona Benta e na sabedoria de Anastácia. Está também fora do humano. Está no quintal, está na mata, nos bichos, nas pedras, nos sapos, nos grilos, em Manoel de Barros, no rio. $E$ depois do rio também. $\mathrm{Na}$ transcendência. No tio Barnabé, que ensina a pegar poesia na peneira. A poesia que, comenta Octávio Paz, jáestáno mundo. Não foi obra de arte. Senão divina.É disso que trato ao produzir para crianças. Caçar poesia com a peneira. Ou tento, como Manoel, sair por aí, "carregando água na peneira", no bolso. "O mesmo que criar peixes no bolso." Ficar "ligado em despropósitos"...

Tem também um jeito de ver o livro como uma coisa grande, que se pode subir encima e sentir-se maior: cultura. Assim como alguém que usa um palanque. Sobe no tablado, pedestal...

No século da ilustração e por meio de um processo de contaminação onde ocupa um papel relevante o aparecimento do termo civilização, a cultura passou a descrever um estado, uma etapa do desenvolvimento humano e sobre esse entendimento pode-se começar a falar que havia pessoas cultas ou incultas, assim como que existiam países civilizados e países selvagens ou não civilizados. Passou assim a ser algo quantificável: tinha-se muita, pouca ou nenhuma cultura. A cultura jánão era, portanto, o processo de cultivo e cuidado das faculdades humanas -a imaginação, a prudência, a Inteligência mas um resultado, ou seja, um "capital", uma soma de bens comensuráveis e, portanto, 
intercambiáveis e factíveis de ser mercantilizados, tal como se fala hoje, por exemplo, da necessidade de contar com "uma cultura empresarial", sem se esquecer que a herança ilustrada daria, também, origem a todo um trajeto político de emancipação onde a cultura e a leitura desempenhavam um claro papel libertador. (BÉRTOLO, 2015, p.71)

Uma ideia da cultura como um lugar que precisasse comprar passagem para chegar. Comprar um acesso à cultura. Como se uma pilha de livros lidos servisse para sentar em cima e ver o mundo do alto. Bem do alto. Como se tivéssemos em um andar superior. Alta cultura. O que pressupõe um andar inferior, baixa cultura. $O$ acúmulo de livros lidos seriam como milhas de viagem. Milhas para trocar por assentos nos bancos altos da cultura. E a falta deles, uma condenação àarena, ao chão, ao baixo, inferior.

A partir dessa consideração, a leitura se apresentava como um caminho de perfeição, como uma via de superação destinada a nos fazer melhores, a nos elevar espiritualmente e, portanto, a sermos merecedores de integrar os níveis superiores dahumanidade. (BÉRTOLO, 2015, p.72)

Fisicamente quando subimos em cima dos livros ficamos mais altos alguns centímetros, é verdade. Faço isso muitas vezes para enxergar um problema do alto. Confesso. No entanto, a altura não me dá clareza maior pela alta cultura em que me coloco. Apenas me modifica o ponto de vista. Muitas vezes no plano dito normal, estamos acostumados a enxergar da mesma maneira. Ou, pior, temos outros objetos e coisas no mesmo plano que atrapalha tal perspectiva. Então, opto por uma perspectiva superior. Acontece que lá de cima não se vê os olhos da gente que passa. Não se sabe que tem sapo, grilo, pedra, cachorro. As crianças na altura dos cachorros fazem perguntas que ninguém, subindo em livro nenhum, nem livro grosso, enxerga resposta.

Por isso, talvez não seja a altura, mas o lado, a outra margem, o aspecto importante da leitura. Ou, talvez não seja a atenção, mas a distração, a transcendência. Reencontrar o desconhecido. Revelar o conhecido. Conhecerse. Tomar distância e consciência, de si mesmo. E voltar, ao ponto de onde saiu, mudado. 
Que ninguém leia por nós para que ninguém seja dono de nossas vidas. Esse é o valor da leitura. Ler para aprender a nos ler no próprio mundo. Essa éa leitura que mete medo nos bombeiros de Fahrenheit. Uma pessoa, um país, uma nação éuma forma própria de ler e de se ler. Uma nação se constrói com o eco civil de uma leitura em voz alta. A leitura constrói nações, mas às vezes fronteiras, abre horizontes, rememora futuros compartilhados, semeia no presente um passado comum. Cria comunidade. (BÉRTOLO, 2015, p.95)

O livro também é feito para o encontro. Como no teatro. $O$ encontro entre o público e os atores. E nesse encontro, a mágica. Produzo livro como quem faz peça. Incitando a mágica do encontro. Éinteressante pensar no livro como o lugar que se pode subir bem alto. E que se pode descer ao chão. Pode conversar com as gaivotas e ouvir o que reclamam as pedras. Ou ainda, entrar para dentro da terra. Escutar um pouco o cochicho da raiz da árvore. E crer nisso tudo junto. Comunidade.

No miúdo, dissemos: a poesia é transcendência. A distração é- não importa se trabalho ou coisa de dom - assustar-se com o mundo já conhecido revelação. E que olhar da outra margem, diferente de onde se vem, éreflexão. Portanto, reflexão é a revelação pela transcendência da poesia alcançada na distração.

Voltemos à ânsia original. Dizia na cabeça do texto, que eu produzo histórias para crianças com o mesmo motivo que escrevo este texto. Então, revelo - porque já é conhecido: reflexão.

O livro para crianças tem para mim uma importância como os sapos e as pedras têm para Manoel de Barros: inútil e essencial. Inútil porque o poema como entende Octávio Paz - tem essa proeza. Ser inútil e carregar em si o essencial - a poesia. O que me interessa no livro infantil éo que escapa entre os dedos. Éa transgressão da linguagem. Poesia. É o falar dos poetas, que não é o falar comum. Éo invisível.É o que revela a poesia na pedra, seu encanto, sua delicadeza, sua infinitude, sem que pedra seja algo novo. Ou também que revela poesia no sapo. Revelar no sapo, sua proeza. Seja na capacidade de virar pedra, como aponta Manoel, ou na sabedoria da necessidade de pular, como em Rosa. Édo cotidiano sabido que trata o mundo dos livros. Mas a poesia, pega esse cotidiano conhecido, transcende e nos faz enxergá-lo, da outra margem. 
A criança recebe o livro para ler. Como um exercício didático do aprendizado na escola. Junta as letras, pesca a palavra, entende a frase e ponto, conhece a história. Mas a história aqui mora na outra margem. Éo poder de estabelecer uma ponte entre o leitor e o texto - o encontro - que o transpõe para o outro lado e o faz enxergar o mundo por uma experiência diferente. Mas o livro ao fazer isso revela o revés. Revela outros lados possíveis. Revela também da linguagem, seu revés: o diabo também mora na linguagem.

Octávio Paz fala da linguagem como algo que inicialmente nos traz uma sensação de segurança. Confiança. Mas também revela que a palavra é rebelde. Foge ao domínio. E cria, nessa fuga, poesia. E aumenta a linguagem. E continuamente amplia, amplia, amplia. A reflexão, o cavar profundo nessa terra fértil que chamamos linguagem tem seus despropósitos. Uma vez cavado, sempre sobra terra ao tentar tapar o buraco. Parece sempre mais terra do que cabe de volta. Como se ela tivesse uma potência de crescer contida. Essa épara mim a primeira importância da leitura: a terra que tira do buraco, não cabe no buraco de volta. Parece que aumenta a terra. Éesse o segredo da linguagem: não tolera aprisionamento.

Mas como se explica isso? Como explicar para alguém que recém aprendeu a conduzir um trem, que ele foge do trilho? Que o batente, aprendido como o caminho a ser seguido, não segura o trem no percurso? E que é justamente nas fugas que se amplia a malha ferroviária desse trem? E que nessas fugas se chega a lugares maravilhosos? Como explicar, se não pelo maravilhamento da poesia? Maravilhamento da transcendência, da revelação na distração, do olhar da outra margem, esse revés do mundo cotidiano. Esse revés do mundo conhecido. O revés da pedra, revés do sapo, a pergunta na altura do cachorro, que desconcerta e entorna gente grande?

É isso o que me prende na produção de livros. E o que me prende na produção desse texto: a reflexão sobre linguagem. O modo muda. A criança trabalha na distração. E éna transcendência da distração que joga. Joga com a linguagem e descobre e inventa os jogos novos dela. Suas regras e brechas. Rachaduras e limos. Aprende a ampliar a linguagem. E na distração se 
interessa pelo revés da vigília o revés da razão e pergunta: O que não estádito? O que se esconde? Por que se esconde?

Já não bastasse a própria literatura provocar toda essa reflexão, o que dizer quando em jogo estão duas linguagens? No hibridismo entre texto e imagem temos a expansão do que cada um tem de potencial, que muitas vezes compensa as limitações da outra. Numa expansão fenomenal.

No trabalho publicado em 2012 (CARVALHO, 2012) apontei, a partir também da reflexão sobre linguagem, recursos propostos por ilustradores para dar conta das limitações na representação imagética. Foi essencialmente uma pesquisa sobre livros de imagens - livros que narram histórias exclusivamente pela imagem. Para isso, a partir de uma comparação entre a linguagem textual, a imagética e a do movimento, procurei dar atenção ao que cada linguagem havia de potencialidade e o que chamei de limitações. Ou seja, o que cada uma tinha mais "facilidade" ou "dificuldade" de representar em uma história. Por exemplo, é notório que a representação visual, dentro desse comparativo, tem potencialmente mais recursos para uma representação espacial. Assim, a tarefa então, foi procurar na linguagem textual, o que ela tinha de potencialidade em relação à linguagem imagética. Ou seja, o que era mais "simples" de representar pelo texto, do que pela imagem. Assim também foi feito com o movimento. E, em última análise, averiguei como os ilustradores davam conta do desafio de representar esses aspectos, unicamente por imagens. Nesse trabalho, encontram-se diversas categorias verificadas a partir dessa análise comparativa, que vale uma leitura afim de compreender o que chamo aqui de "expansão" pelo hibridismo.

A imagem e texto conversam. Nem sempre concordam. Muitas vezes muda o assunto, reforça. Harmoniza, discorda. Ironiza, repete. Dificilmente empata. E assim, nesse duplo, nesse embate, atenta para a humanidade da linguagem. As linguagens ali se afrontam e se amansam. E nesse diálogo que tem briga e tem pazes, vê-se, de tudo que pode cada uma. E mais, revela-se do humano a linguagem. O texto expõe a imagem e essa, por sua vez, devassa o texto, num jogo de limites e sobreposições. 
Um exemplo prático: Como deve ser difícil explicar ironia para criança! Como dizer que o texto fala o inverso do que se pretende ser entendido? $\mathrm{E}$ qualquer outra figura de linguagem? E como são interessantes os livros que a isso se propõem! Colocar em xeque a verdade do texto, pela imagem, por exemplo, ou o contrário, não é confundir, é revelar. É tentar fazer ver o invisível. É fazer compreender que no texto, na linguagem, háde tudo que háno ser humano. Nos mais nobres sentimentos, às perversões. Que há no discurso de comunhão, a discórdia. Que o belo inclui o feio. Que é humana a desumanidade. E que tem, a cada novo buraco cavado, a sobra de terra. E, portanto, mais reflexão a ser feita. Num cavar sem fim que chamamos "Literatura".

Repito, isso tudo é para dizer que o motivo que produzo livro para crianças é o mesmo que escrevo este texto. O sentimento e as razões de inventar histórias para crianças são idênticos ao de inventar questões para a academia: reflexão crítica. Olhar para o produzido e cavar. Cavar e encontrar, na sobra, as dúvidas.

\begin{abstract}
... uma sociedade deve direcionar seus recursos, sempre escassos, em fomentar a leitura, e deveria fazer isso fundamentalmente em apoio aos textos que melhorem essa saúde semântica da sociedade, que ajudem a elevar o nível crítico da sociedade em que vivemos, que permitam desvelar os mecanismos de domínio e consentimento em que transcorrem nossa vida cotidiana, e nos facilitem horizontes de convivência justos e razoáveis." (BÉRTOLO, 2015, p.91)
\end{abstract}

Minha pretensão, portanto, écontribuir, tanto para a literatura infantil quanto para a academia. Propor nos dois universos uma reflexão crítica sobre o texto, sobre a imagem, sobre linguagem. Procurar o ângulo do rio pelo qual posso me ver. E o ângulo cuja imagem do fundo do rio atravessa a lâmina d'água. Atéonde meu olho enxerga. Porque no mundo, como diz Bértolo, para manter-se saudável énecessário sustentar uma reflexão crítica constante. E se não? Teremos cada vez mais terra dura, improdutiva, infértil.

"Com certeza, a liberdade e a poesia a gente aprende com as crianças."

Manoel de Barros 


\section{Referências bibliográficas}

CARVALHO, Miguel. Livro de Imagem e Palhaço Mímico: Narrativas sem palavras?. Pontifícia Universidade Católica do Rio de Janeiro. Rio de Janeiro, 2012.

BÉRTOLO, Consantino. Ler para que? Fronteiras e Horizontes. Revista Emilia. Abril de 2015. Disponível em:http://revistaemilia.com.br/caderno-emiliano-0/. Acessado em Setembro de 2016.

PAZ, Octávio. O Arco e a Lira. Rio de Janeiro: Nova Fronteira, 1982.

BARROS, Manoel de. Poesia completa. São Paulo: Leya, 2010. 